\title{
Malaria Control Mechanisms for Effective Healthcare Delivery in Ghana: The Use of Geographical Information Systems (GIS)
}

\author{
Lenos Koku Ankrah ${ }^{1}$, Desmond Ayim-Aboagye ${ }^{2}$, Franklin N. Glozah ${ }^{2}$ \\ ${ }^{1}$ Learning Resource Centre, Regent University College, Accra, Ghana \\ ${ }^{2}$ Department of Psychology, Regent University College, Accra, Ghana \\ Email: "lenos.ankrah@regentghana.net
}

Received 25 January 2016; accepted 26 February 2016; published 29 February 2016

Copyright (C) 2016 by authors and Scientific Research Publishing Inc.

This work is licensed under the Creative Commons Attribution International License (CC BY). http://creativecommons.org/licenses/by/4.0/

(c) $\underset{\mathrm{EY}}{0}$ Open Access

\begin{abstract}
Malaria is a major health problem facing many tropical countries, including Ghana. The use of modern mechanisms to study environmental factors in malaria occurrence is imperative in malaria control efforts. The aim of this research is to investigate how malaria occurrence is influenced by environmental factors and how Geographical Information Systems (GIS) can be used as a mechanism for improving malaria control in healthcare delivery in Ghana. Environmental factors, elevation, daily temperature and daily rainfall were plotted against prevalence of $M$ and $S$ forms of mosquitoes using ArcGIS 10.1. Prevalence of Anopheles gambiae $M$ was the highest at elevations of $0 \mathrm{~m}$ to $200 \mathrm{~m}$ and that of $S$ was the highest at elevations between $200 \mathrm{~m}$ and $500 \mathrm{~m}$. Prevalence of $M$ was the highest at temperatures between $26.1^{\circ} \mathrm{C}-27.6^{\circ} \mathrm{C}$ whilst that of $S$ was the highest at temperatures of between $24.5^{\circ} \mathrm{C}$ and $26.0^{\circ} \mathrm{C}$. Prevalence of $\mathrm{M}$ was the highest at rainfall between 10 $\mathrm{mm}$ and $35 \mathrm{~mm}$ and $S$ was the highest at rainfall between $26 \mathrm{~mm}$ and $36 \mathrm{~mm}$ and beyond. $M$ form was positively correlated with temperature and negatively with elevation and humidity. The $S$ form was negatively associated with temperature and positively with elevation and rainfall. GIS models can combine with environmental data to estimate vector prevalence under environmental conditions and therefore its use is recommended in Ghana.
\end{abstract}

\section{Keywords}

Malaria, Geographic Information Systems, Healthcare, Ghana

\footnotetext{
${ }^{*}$ Corresponding author.
} 


\section{Introduction}

Malaria occurrence is prevalent in Ghana and it is the leading cause of illness; about 8200 reported cases daily; 3,000,000 illnesses yearly; and over 3000 deaths in the year 2010 alone [1]. Unsurprisingly, Ghana ranks third in malaria occurrence in Africa [2]. Malaria is a vector-borne disease which is strongly influenced by environmental factors and individuals get this disease through mosquito bites [3] [4]. Anopheles gambiae s.s is the most pervasive of all the complex gambiae mosquito species, in the cause of malaria [5]. The sensu stricto forms of the Mopti (M) and Savanna (S) strains constitute the most pervasive group of mosquitoes in relation to the transmission of malaria in Ghana, and it is diagnosed using microscopy where blood smears are taken from a finger prick and studied under a microscope to ascertain the presence or otherwise of the parasite [6]. These types of mosquitoes represent the most dangerous parasites in Africa, South of the Sahara. In particular, the most dangerous form of malaria parasite is the plasmodium falciparum, which produces clinical features such as fever, anaemia, respiratory distress (acidosis), hepatosplenomegaly (simultaneous enlargement of both the liver and the spleen) and hypoglycaemia (deficiency of glucose in the bloodstream) as well as labor and foetal death among expectant mothers [7]. It has been asserted that Geographical Information Systems (GIS) could be used to map environmental factors that influence the occurrence of malaria [8], because environment factors have a substantial influence on malaria occurrence, which could be treated through the use of drugs such as quinine, doxycycline, artemether with lumefantrine, as well as atovaquone with proguanil [4] [9]. Accordingly, health care institutions could use GIS to develop innovative ways to harness the data integration with spatial visualization power of GIS to produce malaria risk maps, implement, monitor, and evaluate, malaria control policies and programs in more effective and efficient ways in efforts aimed at controlling malaria. Also, GIS has huge potentials to help improve the management of electronic medical records, medical personnel and other health resources in relation to malaria in Ghana [10].

\subsection{Malaria as a Public Health Concern in Ghana}

The major climatic conditions in Ghana include tropically warm and relatively dry air along the Southeast coast; hot and humid in Southwest; hot and dry in the North tropical rainforest and mountainous forest [11]. Ghana's ecology can be separated into six different zones; the coastal savanna, the mangrove zones at the coastline, the moist semi-deciduous forest in the central area, the evergreen forest in the south-west, the guinea savanna in the north and the Sudan savanna in the north-east. The country's terrain is mainly low plain, with a dissected plateau along its south-central area. Ghana experiences two main raining seasons; one from March to May and the second from September to October. It is generally dry from the month of November to March.

The environment in Ghana is conducive for interactions between the anopheles mosquito, malaria parasites and human hosts. Socio-political conditions, low level of health consciousness and poverty in the country combine with the varied climatic conditions, sanitation problems, vegetation and biogeography combine to explain the conditions for malaria occurrence in Ghana [3]. Malaria is the number one cause of morbidity accounting for $40 \%$ of outpatient attendance with annual reported cases of 2.2 million between 1995-2001, over $10 \%$ ending up on admission, and 9\% of maternal deaths in 2007 [12]. The average Proportional Mortality Rate (PMR) of Malaria in Ghana is $17.3 \%$ [13], and the disease is hyper endemic with a crude parasite rate ranging from $10 \%-70 \%$ and plasmodium falciparum the major dominating malaria parasite [14].

Malaria infections has costed Ghana about 850 million cedis (US \$94 million) for treatment alone over the years [15]. By deduction, these figures may be an underestimate of the real burden, as many cases go unreported and the disease continues to negatively affect the development prospects of Ghana. Also, the annual economic burden of malaria in Ghana is estimated to be between 1 - 2 per cent of the Gross Domestic Product [14].

In addition, malaria is the leading cause of school and work absenteeism and significantly affects socioeconomic development because even if a child survives death, the consequences from severe malaria such as convulsions or brain dysfunction hamper long-term development and schooling [16]. In some areas of Ghana, as many as $30 \%$ of children engagement with school is impaired as a result of repeated bouts of malaria [14].

Despite all these facts, there is inadequate provision of basic anti-malaria health infrastructure such as drains, rubbish dumps, descent sewage systems, descent public toilet facilities, public mosquito spray facilities in Ghana in order to reduce the breeding of the parasite in the communities. Also, although several efforts have been made to fight malaria in Ghana, a lot more needs to be done by using modern mechanisms. 


\subsection{GIS for Malaria Control in Ghana}

GIS can be used to forecast the dynamics of the links between the occurrence of diseases and environmental parameters such as temperature, humidity, sanitation, rainfall, and vegetation. GIS reserve spatial modeling capacity that can be used to derive information about spatial relationships between various health related geographic phenomena [14]. Mosquitos' movements are constrained only by flight distances, measured in one vector species at a maximum distance of $1.8 \mathrm{~km}$, and could be used to generate models of malaria occurrence, seasonality and transmission intensity [17] [18]. The outputs of such models can be combined with population data to estimate population exposure, mortality and morbidity and to analyze and project the effects of climate change on malaria [19]. As health care facilities, hospital wards, infrastructure and logistics are inadequate in Ghana, GIS could be used to examine inequalities in population per bed ratios in big hospitals. It would also be possible to use a GIS-based system, Patient Location and Care Environment System (PLACES), to enable health providers see the physical bed location of each patient and to retrieve demo-graphic and clinical information.

In addition, GIS could be used to create modal patterns of clinic attendance around an integrated rural health facility and can be used to develop relevant data that can be analyzed to show the relative attraction of various health facilities in the districts. For the sake of the implementation of appropriate actions regarding time, judicious and accurate information on the occurrence of malaria disease, it is crucial that GIS is used to generate clinical information that can be disseminated in a visual and geographic manner, such that it could readily be understood by users. This could provide a quick access to medical records which is critical to effective treatment of malaria. With a practically nonexistence of the use of electronic medical records (EMR) in hospitals in Ghana, GIS could be used to build EMR by pursuing a patient-centric approach that focuses on the development of information around patients, in contrast to the approach used by the current system in Ghana, that builds information around each episode or encounter a patient has with the health care system.

Therefore, the objectives of this research were to investigate environmental conditions that influence the distribution of mosquito species that cause malaria, use GIS (overlay analysis) to correlate the occurrence of malaria causing mosquitoes and the environmental conditions that create them and to map out malaria risk areas of the country.

\section{Methods}

The main approach of this research was the use of secondary data on environmental factors and Anopheles gambiae sensu stricto (gambiae s.s) mosquitoes in Ghana to demonstrate correlation between environmental factors and the prevalence of the malaria causing mosquitoes using GIS.

\subsection{Study Site}

The study on the occurrence of malaria causing mosquitoes was done to cover the whole of the country. Even though the collection of secondary data on the occurrence of these mosquitoes was not done to cover every part of the country, the data collected was quite representative of the various regions of the country. The Northern, the Middle zones and the Southern parts of the country were covered. The method used depended on the location of the study sites. Irrespective of the collection method used, data collected from the same location in different years were considered separately. The data collected spanned from the years 2000 to 2010. It is worth noting that these where the latest data available at the time this study was actually conducted.

\subsection{Data Use}

To investigate the geographical and environmental factors that influence the occurrences of Anopheles gambiae $\mathrm{M}$ and S species, secondary data were used to examine the spatial distribution of the mosquitoes in Ghana. The complex gambiae mosquito species consist of Anopheles arabiensis, Anopheles bwambae, Anopheles merus, Anopheles melas, Anopheles quadriannulatus and Anopheles gambiae sensu stricto. Geographic sources-maps, remote-sensed satellite sources, and geographic databases were used to obtain data such as the vector's existence in parts of the country and their associated environmental conditions. Most of the data were collected from the Center for Remote Sensing and Geographical Information Services (CERSGIS), University of Ghana. Data on collection methods of the mosquitoes, location, sample size, study period, mosquito species and molecular forms were collated into a database. Mosquito collection methods (pyrethroid spray catches, human landing catches, 
larval collections and aspirators) were used to determine the number of the species of mosquitoes in the area. The collection of data on the occurrence of malaria causing mosquitoes was done to match the environmental factors in which they occurred. It was more convenient to collect the two variables together from the same source, as these were available together. It may have been inappropriate for purposes of analysis and interpretation if these were collected at different times or through different methods.

\subsection{Data Analysis}

Statistical analyses were conducted with Statistical Package for Social Science (SPSS 19) software. Bar graphs were used to show the averages of gambiae $\mathrm{M}$ and $\mathrm{S}$ and environmental factors. Pearson correlation analysis was used to examine the relationships between Anopheles gambiae s.s and environmental variables. The three environmental factors; elevation, daily temperature and daily rainfall, were correlated with prevalence of $\mathrm{M}$ and $\mathrm{S}$ forms of mosquitoes. The availability of anopheles $\mathrm{M}$ and $\mathrm{S}$ were used separately as dependent variables and the environmental factors were used as independent variables. All correlation coefficients were examined at 0.05 level of significance.

\subsection{Ethical Consideration}

The primary data originators, CERSGIS at the University of Ghana, obtained ethical approval from Ghana National Ethics Committee. This research was carried out with high level of ethical standards, especially in relation to data collection and use of the data. An approval to use the data for this study was granted by the primary data originators before the data were accessed and used.

\section{Results}

\subsection{Environmental Factors and Gambiae $\mathrm{M}$ and $\mathrm{S}$}

The results show that environmental factors affect the distribution of gambiae M and S. With the Anopheles gambiae S prevalence was highest at elevations between $200 \mathrm{~m}$ and $500 \mathrm{~m}$ (Figure 1).

Anopheles gambiae M prevalence was found to be highest at elevations of between $0 \mathrm{~m}$ and $200 \mathrm{~m}$. With the Anopheles gambiae $\mathrm{S}$ the prevalence was found to be highest at elevations between $200 \mathrm{~m}$ and $500 \mathrm{~m}$ (Figure 2).

With gambiae $\mathrm{S}$, prevalence was found to be highest within rainfall ranges of between $26 \mathrm{~mm}$ and $36 \mathrm{~mm}$ and beyond (Figure 3).

With gambiae $\mathrm{M}$, the highest prevalence ranged between $10 \mathrm{~mm}$ and $35 \mathrm{~mm}$ mean daily rainfall (Figure 4).

With the Anopheles gambiae S, the prevalence was highest at daily mean temperatures that ranged between $24.5^{\circ} \mathrm{C}$ and $26.0^{\circ} \mathrm{C}$ (Figure 5).

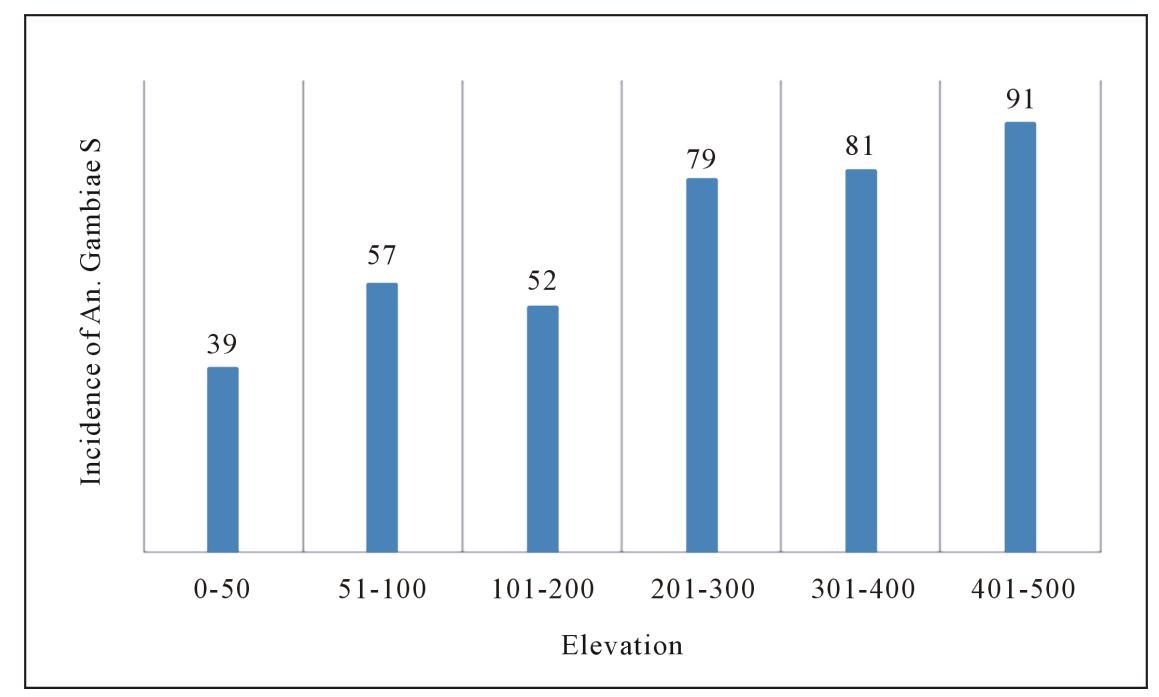

Figure 1. Prevalence of gambiae S and elevation. 


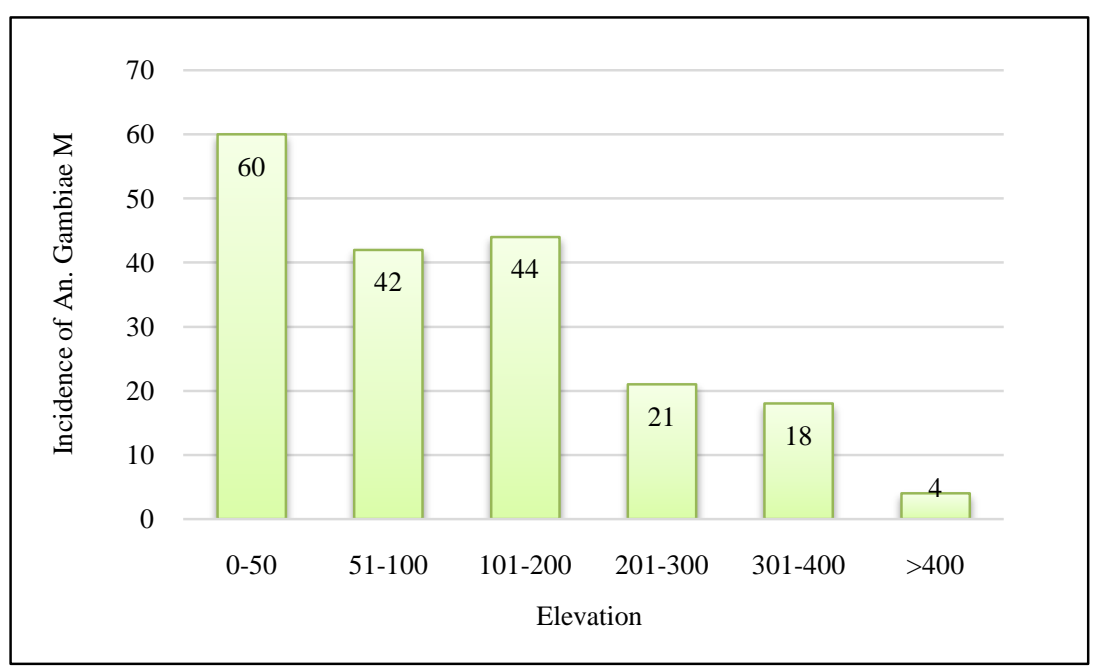

Figure 2. Prevalence of gambiae $\mathrm{M}$ and elevation.

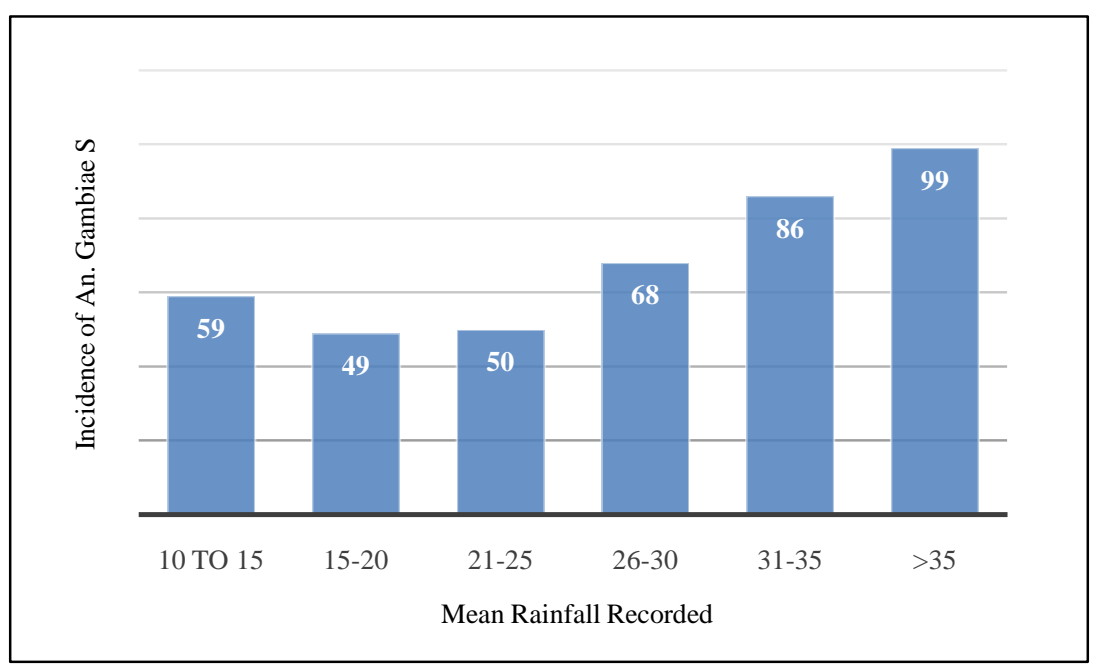

Figure 3. Prevalence of gambiae S and daily rainfall.

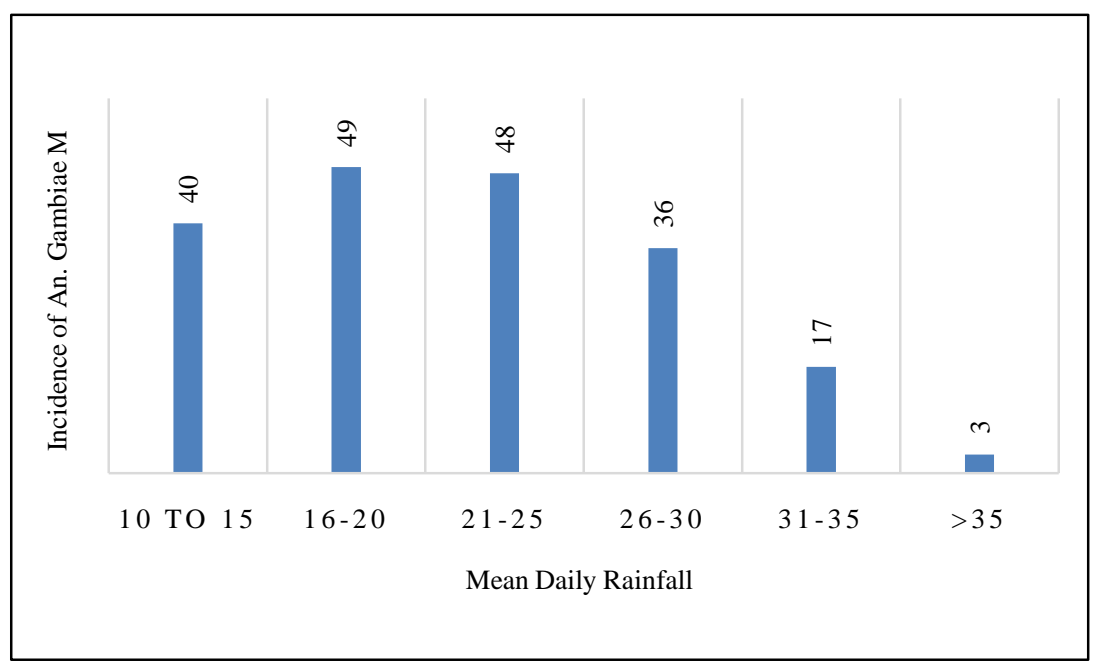

Figure 4. Prevalence of gambiae M and daily rainfall. 
The gambiae M prevalence was found to be highest at mean daily temperatures that ranged between $26.1^{\circ} \mathrm{C}$ $27.6^{\circ} \mathrm{C}$. With the gambiae $\mathrm{S}$, the prevalence was highest at daily mean temperatures that ranged between $24.5^{\circ} \mathrm{C}$ and $26.0^{\circ} \mathrm{C}$ (Figure 6).

\subsection{Types of Gambiae and Environmental Factors}

Table 1 shows the relationship between the prevalence of Anopheles gambiae forms and environmental factors. The Anopheles gambiae $\mathrm{M}$ had a significantly positive association with temperature and negatively with elevation and Humidity. The $\mathrm{S}$ gambiae was found to have a significant negative relationship with temperature and positively with elevation and rainfall.

\subsection{Types of Anopheles gambiae Mosquitoe Distribution}

Figure 7 shows that in most cases the Anopheles gambiae $\mathrm{M}$ and $\mathrm{S}$ forms occurred together. The $\mathrm{M}$ forms of the Gambiae mosquitoes were prevalent in the northern and coastal savanna regions whilst the Gambiae $S$ forms were more prevalent in the central and southern parts of Ghana. The Anopheles gambiae $\mathrm{M}$ and $\mathrm{S}$ forms were sympatric in most locations. The $\mathrm{S}$ form predominated in the central region, while the $\mathrm{M}$ form predominated in the northern and coastal savanna regions.

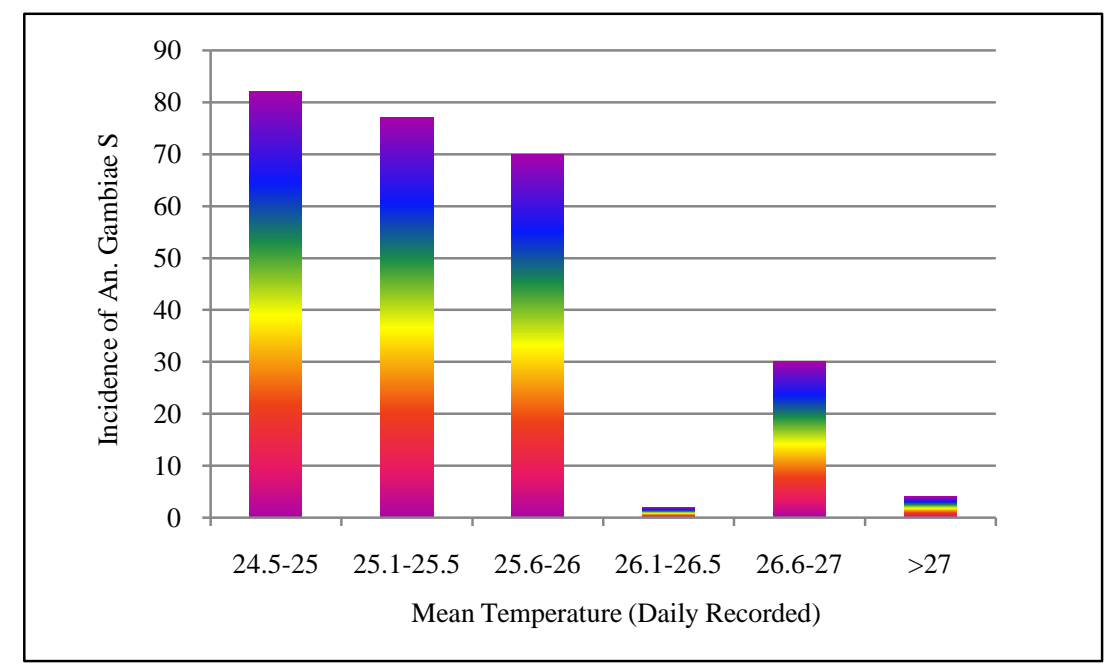

Figure 5. Prevalence of gambiae S and daily rainfall.

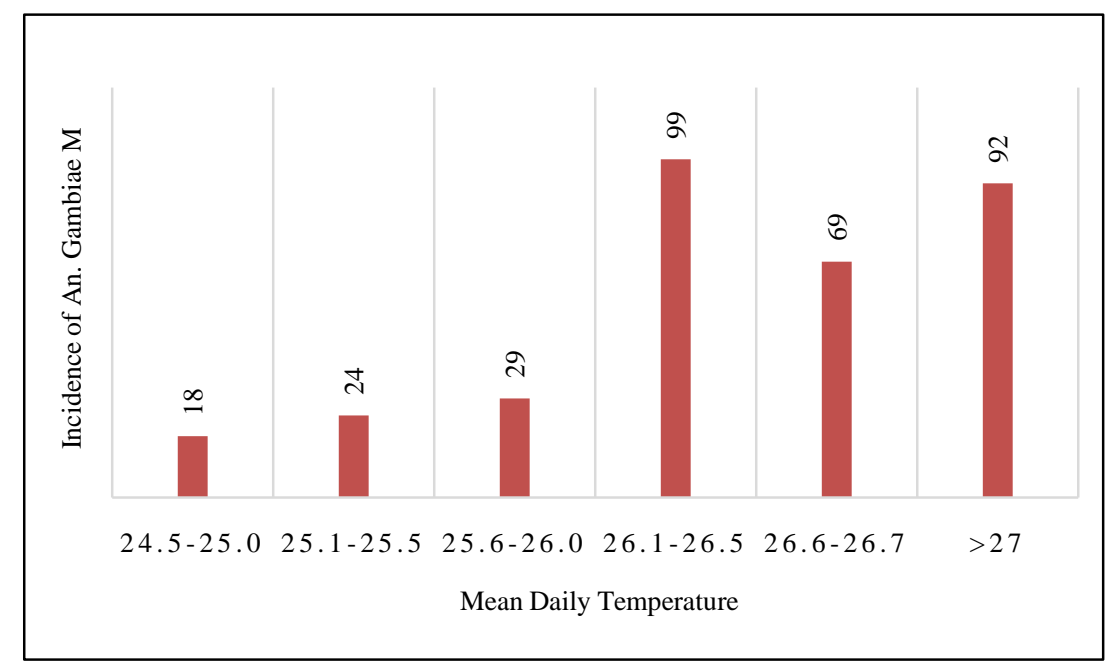

Figure 6. Prevalence of gambiae $\mathrm{M}$ and daily temperature. 
Table 1. Relationship between forms of gambiae and environmental factors.

\begin{tabular}{|c|c|c|c|c|c|c|}
\hline \multirow{2}{*}{$\begin{array}{l}\text { Environmental } \\
\text { factors }\end{array}$} & \multicolumn{2}{|c|}{$\begin{array}{l}\text { Combined methods } \\
\qquad \mathrm{N}=71\end{array}$} & \multicolumn{2}{|c|}{$\begin{array}{l}\text { Human landing catch } \\
\qquad \mathrm{N}=25 \\
\text { Anopheles gambiae }\end{array}$} & \multicolumn{2}{|c|}{$\begin{array}{l}\text { Larval collection } \\
\qquad \mathrm{N}=29\end{array}$} \\
\hline & M & S & M & S & M & S \\
\hline Elevation & $-0.29^{*}$ & $0.30^{*}$ & $-0.54^{* *}$ & $0.58^{* *}$ & $-0.42^{*}$ & $0.51^{* *}$ \\
\hline Temperature & $0.52^{* *}$ & $-0.58^{* *}$ & $0.62^{* *}$ & $-0.71^{* *}$ & 0.15 & $-0.42^{* *}$ \\
\hline Rainfall & $-0.33^{* *}$ & $0.40^{* *}$ & $-0.63^{* *}$ & $0.75^{* *}$ & $-0.39^{*}$ & $0.61^{* *}$ \\
\hline Humidity & $-0.26^{*}$ & 0.08 & -0.06 & -0.11 & 0.19 & -0.43 \\
\hline
\end{tabular}

${ }^{*} p<0.05,{ }^{* *} p<0.01$ (two tailed).

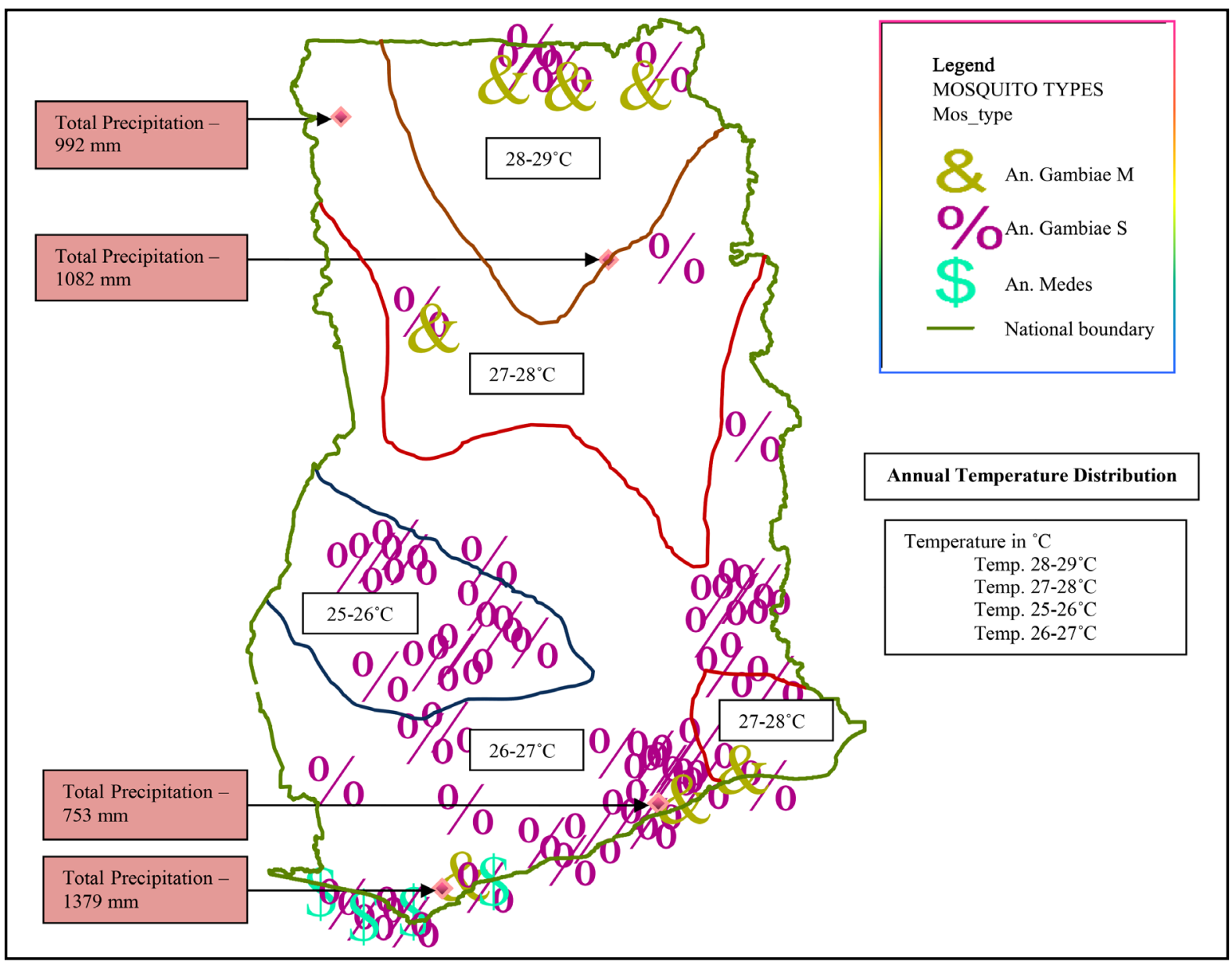

Figure 7. Thematic map of types of Anopheles gambiae mosquito distribution in Ghana.

\section{Discussion}

This study sought to use GIS to examine the relationship between gambiae forms and environmental factors as well as examine types of Anopheles gambiae mosquitoe distribution in Ghana. The distribution of the $\mathrm{M}$ and $\mathrm{S}$ mosquitoes is influenced by environmental factors and ecological zones, similar to findings of previous studies [4]. Also the distribution of the M and S mosquitoes is influenced by human population changes and anthropological effects, which may lead to land-use changes ultimately affecting vector distribution and abundance, consistent with previous findings [20]. 
Results of environmental analyses indicate that elevation, rainfall, temperature and humidity are important variables driving the spatial distribution of each mosquito species [17] [18]. Temperature appears to be a key factor distinguishing the other species; probably due to conditions of their production. The Anopheles gambiae $\mathrm{M}$ form was more prevalent and seemingly better adapted to higher temperatures, than the $\mathrm{S}$ form. This is consistent with the findings that the gambiae $\mathrm{M}$ form shows a more latitudinal range in Ghana than the S form [21]. This is due to the fact that it is the most dominant form prevalent in warm/hot areas in the northern regions of Ghana. Mosquitoes generally develop and multiply faster and feed earlier in their life cycle at higher frequency in warmer climatic conditions [20]. Rainfall is largely responsible for creating the conditions which allow sufficient surface water for mosquito breeding sites because it generates surface water in which mosquitoes can lay their eggs [22].

Whilst larger numbers of gambiae $\mathrm{M}$ species were collected at lower elevation, the $\mathrm{S}$ form was denser at higher density; but generally more of the two types were collected at lower elevations than the higher levels. This may be due to increased human disruption in the lower elevation, creating more favorable breeding places than at higher elevations. Another cause may be related to dispersal of mosquito, since they have to stop while flying to refuel with blood/nectar, which they can only do at lower elevations where human activities abound. Elevation's influence could also be due to its modifying effect on temperature and humidity because humidity has an impact on the survival rate of mosquitoes as well [17]. Mosquitoes will generally not leave long enough to complete their transmission cycle where and when the relative humidity is consistently less than $60 \%$ [22]. Generally, these variables create conditions suitable for malaria transmission every year.

The use of GPS to gather survey data for GIS use could lead to a substantial increase in the number of geo-referenced health projects in Ghana. A strategy of developing a self-paced training package that can be used to train individuals could possibly be used to customize some GIS software to minimize end-user skill requirements for its use [23]. Programmers in Ghana could be sensitized to take up the tasks of producing these packages or softwares.

To prevent the spread of mosquitoes the control of larvae and pupae to prevent their development into adult mosquitoes is critical. Do to this, receptacles that can contain water should be turned over, thrown away, or emptied to prevent them from containing rain or any other stagnant water; tight lids must always be placed on containers used for water storage; stored water should regularly be verified to ensure that there are no larvae or pupae contained in the stored water. Prevention can be best achieved by emptying containers that contain eggs, washing walls with brushes to remove eggs; regularly clean and replace water in animal drinking containers and wash bowls regularly to ensure that mosquito eggs are washed away as soon as they are laid; regularly empty and clean drains and terrains that can contain stagnant water; broken septic tanks and cover vent pipes should be repaired immediately they are damaged with wire mesh; water in swimming pools should be constantly drained and replaced and appropriately chlorinated; screens or wire nettings should be used to cover windows and make trap doors in addition to main doors; and repellents such as N-diethyl-m-toluamide or Picaridin should be sprayed on clothing and exposed skin.

In spite of the foregoing, this study has a few limitations. This study essentially focuses on examining how GIS could be used to map malaria risk areas. The study depended entirely on previously collected data on anopheles mosquito species data and corresponding environmental factors and not primary data which may poses questions of relevance in terms of how recent the data. Also, the secondary data used for the study was based on a relatively small number of Anopheles gambiae $\mathrm{M}$ and S mosquitoes in Ghana using only a small number of collection sites, which may not be very representative of the whole mosquito population in Ghana. It will be interesting for future studies to use more representative dataset to replicate this study which could, in addition to showing more geographical environmental factors responsible for mosquitoes "species" and distribution can also provide precise spatial limits of the mosquitoes' distributions in the country. It is recommended that public health agencies in Ghana should manage geo-referenced health records by aggregating health record data at the census tract level so that the privacy of individual patients would be preserved while allowing easy access to data through the use of an ArcView GIS query tool. Finally, as the data used for this study is getting quite old, future studies should consider the data and results of this study vis-à-vis the latest available data.

\section{Conclusion}

GIS is an effective technology for understanding and monitoring geographic or environmental conditions 
vis-a-vis their relationships with malaria incidence in order to limit the impact of disease. The nature and high magnitude of Ghana's disease burden due to high malaria prevalence and the potentials that GIS holds to reduce that problem makes the need for this technology crucial in Ghana. GIS is an appropriate technology that could be used for malaria control efforts for effective healthcare delivery in Ghana.

\section{Acknowledgements}

The authors would like to thank the researchers at CERSGIS, University of Ghana who collected the data as well as the authorities who gave approval for the data to be used for this study. We thank the reviewers, whose comments, greatly improved the quality of this article.

\section{Conflict of Interest Statement}

The authors declare that they have no conflicts of interest.

\section{Author Contribution}

LKA conceived the research idea and conducted the study, generally. All authors contributed to literature search, review and data analysis. LKA and FNG drafted the manuscript. All authors contributed to writing as well as approved the final version of the manuscript.

\section{Author Information}

Lenos K. Ankrah: Lecturer in Geographic Information Systems, School of Business and Leadership, Regent University College.

Prof. Desmond Ayim Aboagye: Vice-president (Academic Affairs), Regent University College.

Dr. Franklin Glozah: Dean, Faculty of Arts and Sciences, Regent University College.

\section{References}

[1] Sodzi-Tettey, S. (2011) Malaria Control in Ghana: Challenges and Opportunities. http://www.ghanaweb.com/GhanaHomePage/NewsArchive/artikel.php

[2] World Health Organization (2000) The World Health Report 2000. Health Systems: Improving Performance. World Health Organization, Geneva.

[3] Kumordzie, E. (1993) The Ecological Power of Health and Disease in Ghana. Kekeli Press, Accra.

[4] Zhou, G., Munga, S., Minakawa, N., Githeko, A.K. and Yan, G. (2007) Spatial Relationship between Adult Malaria Vector Abundance and Environmental Factors in Western Kenya Highlands. American Journal of Tropical Medical Hygiene, 77, 29-35.

[5] Appawu, M.A., Baffoe-Wilmot, A., Afari, E.A., Nkrumah, F.K. and Petrarca, V. (1994) Species Composition and Inversion Polymorphism of the Anopheles gambiae Complex in Some Sites of Ghana, West Africa. Acta Tropica, 56, 1523. http://dx.doi.org/10.1016/0001-706X(94)90036-1

[6] Boakye, D.A., Wilson, M.D., Appawu, M.A. and Gyapong, J. (2004) Vector Competence of Anopheles Mosquito Populations in the Bongo District of Ghana to Wuchereria bancrofti. Annals of Tropical Medicine and Parasitology, 98, 501-508. http://dx.doi.org/10.1179/000349804225003514

[7] Giles, G.M. (1902) A Handbook of the Gnats or Mosquitoes Giving the Anatomy and Life History of the Culicidae Together with Descriptions of All Species Noticed up to the Present Date. London, John Bale, Sons \& Danielsson, Limited.

[8] Ajayi, E. and Olayinka, G. (2007) Benefits of GPS Data Integration into GIS: Chevron Nigeria Experience. www.proceedings.esri.com/library/userconf/survey07/summit/...2014.pdf

[9] Binka, F.N., Morris, S.S., Ross, D.A., Arthur, P. and Aryeetey, M.E. (1994) Patterns of Malaria Morbidity and Mortality in Children in Northern Ghana. Transactions of the Royal Society of Tropical Medicine and Hygiene, 88, 381-385. http://dx.doi.org/10.1016/0035-9203(94)90391-3

[10] Adu-Praha, S. and Tetteh, E.K. (2015) Spatiotemporal Analysis of Climate Variability Impacts on Malaria Prevalence in Ghana. Applied Geography, 60, 266-273. http://dx.doi.org/10.1016/j.apgeog.2014.10.010

[11] Stock, R. (1995) Africa South of the Sahara: A Geographic Interpretation. Guilford Press, New York.

[12] UNICEF (2007) Ghana Factsheet, Malaria. www.Unicef.org/wcaro/GhanaFactsheetmalaria 
[13] Adams, I., Darko, D. and Sandro, A. (2004) Malaria: A Burden Explored. Bulletin of Health Information, 1, 21-27.

[14] Asante, F. and Asenso, O. (2003) Economic Burden of Malaria in Ghana: A Technical Report Submitted to the WHO Africa Regional Office.

[15] Akosa, K. (2006) Fighting Malaria in Ghana. www.ghanahealthservice.org

[16] Krefis, A.C., Schwarz, N.G., Nkrumah, B., Acquah, S., Loag, W., Sarpong, N., Adu-Sarkodie, Y., Ranft, U. and May, J. (2010) Principal Component Analysis of Socioeconomic Factors and Their Association with Malaria in Children from the Ashanti Region, Ghana. Malaria Journal, 9, 201. http://dx.doi.org/10.1186/1475-2875-9-201

[17] Hay, S.I., Snow, R.W. and Rogers, D.J. (1998) Predicting Malaria Seasons in Kenya Using Multitemporal Meteorological Satellite Sensor Data. Transactions of the Royal Society of Tropical Medicine and Hygiene, 92, 12-20. http://dx.doi.org/10.1016/S0035-9203(98)90936-1

[18] Craig, M.H., Snow, R.W. and le Sueur, D. (1999) A Climate-Based Distribution Model of Malaria Transmission in Sub-Saharan Africa. Parasitology Today, 15, 105-111. http://dx.doi.org/10.1016/S0169-4758(99)01396-4

[19] Yieleh, C. (2013) Shortage of Trained Midwives Undermining MDG's 4 and 5. www.edition.myjoyonline.com/pages/news/201305/105536.php

[20] Yawson, A.E., Weetman, D., Wilson, M.D. and Donnelly, J. (2007) Ecological Zones Rather than Molecular Forms Predict Genetic Differentiation in the Malaria Vector Anopheles gambiae s.s. in Ghana. Genetics, 175, 751-761. http://dx.doi.org/10.1534/genetics.106.065888

[21] Kirby, M.J. and Lindsay, S.W. (2008) Effect of Temperature and Inter-Specific Competition on the Development and Survival of Anopheles gambiae sensu stricto and Anopheles arabiensis Larvae. Acta Tropica, 109, 118-123. http://dx.doi.org/10.1016/j.actatropica.2008.09.025

[22] Grover-Kopec, E.K., Blumenthal, M.B., Ceccato, P., Dinku, T., Omumbo, J.A. and Connor, S.J. (2006) Web-Based Climate Information Resources for Malaria Control in Africa. Malaria Journal, 5, 38. http://dx.doi.org/10.1186/1475-2875-5-38

[23] Asuo-Mante, E., Awoonor-Williams, J.K., Yelifari, L., Boyer, C., Schmitt, M.L. and Phillip, J.F. (2016) The Application of Geographic Information Systems (GIS) to Improving Health Systems in the Upper East Region of Ghana. Journal of Global Health Care Systems, 6, 1-14. 